\title{
Mehr als Federn
}

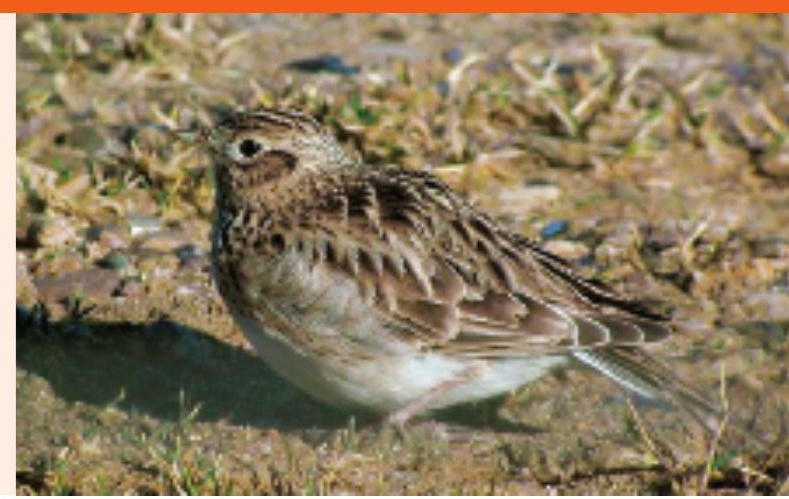

Am frühen Abend wird das Quartier zur Volière. Ein vielstimmiges Konzert von Amsel, Blaumeise, Türkentaube, Buchfink, Girlitz und Sperling. Das geübte Ohr von Nico Schwarzenbach nennt weitere Solisten, die ich bloss dem Namen nach kenne. Etwas vom Schönsten sei für ihn, in aller Frühe durch ein Ried zu wandern und jede Nuance dieses Gesanges in sich aufzunehmen. Nico Schwarzenbach, geboren 1957, wohnt hier mit Frau und zwei Kindern. Er ist Allgemeinpraktiker und seit zehn Jahren Obmann der Herisauer Vogelschützer. Die Grossmutter schenkte dem Knaben ein Fernglas, das Interesse an der Natur wurde früh geweckt und hat seither nie mehr nachgelassen.

In seiner Untersektion vom Dachverband BirdLife Schweiz wird das ganze Jahr sehr viel Arbeit geleistet. Es braucht diplomatisches Geschick, wenn Baubehörden, Architekten, Denkmalschutz und Auftraggeber vom Nächstliegenden überzeugt werden müssen. Nur so werden Nistkästen angebracht und Dachuntersichten mit wenig Aufwand zu Bruträumen umfunktioniert. So kommt das Altersheim zu einer Vogelkolonie, das Kirchgemeindehaus bietet Schlupflöcher und die Landesverteidigung gewährt am Zeughaus dem geflügelten Nachwuchs eine Heimat. Auf dem höchsten Spitaldach steht ein grosser Kasten für den Alpensegler bereit, er muss ihn nur noch für gut befinden. 200 Stunden Fronarbeit im Jahr bedeuten auch harte Bodenarbeit: das Aufwerten von Hecken mit Ausholzen und Anpflanzen von Holunder, Schwarzdorn, Liguster, Heckenkirsche und Pfaffenhut. Die Jäger sind froh um Projekte, mit denen sie ihrer Hegepflicht nachkommen können, Schulklassen setzen den Biologieunterricht in die Praxis um, öffentliche Führungen und Exkursionen vermitteln Anleitung und Wissen. Ein zäher Partner ist die Landwirtschaft und nur steter Tropfen höhlt das politische Gestein. Es braucht nimmermüde Optimisten mit sehr viel Ausdauer, um bei Nutzungsplänen, Friedhofsgestaltung, Parkanlagen und Strassenböschungen mitreden zu können. Auch einem Obmann sind enge Grenzen gesetzt, und er wird fast etwas neidisch, wenn er an Zürcher Verhältnisse denkt. Viele Bauherren seien schlecht informiert und durchaus bereit, nach entsprechender Aufklärung, ihre Rasenwüsten einzudämmen und von Cotoneaster, Thujahekken und Forsythien abzulassen. Auch nach jahrelanger Information sei das vernetzte Denken alles andere als selbstverständlich. Wenn Nico Schwarzenbach auf seine zehn Präsidialjahre zurückblickt, zieht er eine gemischte Bilanz. Da sind die 1500 allein in diesem Frühjahr angepflanzten Büsche, die Mauersegler in Nachbars Garten und die Käuzchen nebenan. Doch die Arbeit des Vereins der 90 Vogelfreunde gleicht einem Wettlauf gegen die Zeit. Wiesenbrüter wie Lerchen und Braunkehlchen sind im ganzen Alpsteingebiet der intensiven Graswirtschaft zum Opfer gefallen, hochstämmige Obstbäume verschwinden, Sümpfe und Magerwiesen sind nur noch in kleinsten Parzellen vorhanden. Auch Biotope und Nistkästen können den Artenschwund nur bremsen. Lokale Erfolge werden durch den Strassenausbau und die scheinbar unaufhaltsame Zersiedelung wieder aufgehoben. Das Prinzip Hoffnung hilft auch hier und die Freude am Gelungenen, etwa an der neuen Bruchsteinmauer, an den Krötenkaulquappen im Teich, am Igel vom Vorjahr und an den vielen Wundern, die sich dem erschliessen, der dafür offen ist.

Viele helfen mit. Ohne das Verbandsbeschwerderecht von rund 16 Umweltorganisationen ginge die Reise in den Abgrund noch schneller vor sich. Trotz den jährlich über 100000 Baubewilligungen werden die meisten Streitfälle unbürokratisch gelöst, und $84 \%$ aller Fälle wurden 2005 ohne Gerichte erledigt. Nur fünfmal gelangten die Parteien ans Bundesgericht, das in vier Fällen im Sinne der Natur entschied. Wie ist es zu erklären, dass eine marode Staatspartei mit sehr viel Geld das 40jährige Verbandsbeschwerderecht unserer Heimat-, Natur- und Umweltverbände abschaffen möchte? Nico Schwarzenbach hat darauf nur eine Antwort, er drückt mir ein Faltblatt in die Hand: «JA! Ich werde Mitglied der Ornithologischen Gesellschaft Herisau.»

Und noch eine Adresse, die sich für alle Restschweizer lohnt: www.vogelwarte.ch. 